\title{
Early outcome of vascular lower limb amputations at a National Referral Hospital in Kenya
}

\begin{abstract}
K.O. Awori, MBChB, MMed (Surgery), Assistant Lecturer, Department of Human Anatomy, School of Medicine, University of Nairobi and Consultant Surgeon, Division of Orthopaedics, Kenyatta National Hospital, Nairobi, Kenya. J.E.o. Ating'a, MBChB, MMed (Surgery). M.Ch (Ortho), Associate Professor, Department of Orthopaedic Surgery, School of Medicine, University of Nairobi and Consultant Surgeon, Division of Orthopaedics, Kenyatta National Hospital, Nairobi, Kenya, P.O. Box 19676- 00202, Nairobi, Kenya
\end{abstract}

Corresponding author: Dr. K.O. Awori, Department of Human Anatomy, School of Medicine, University of Nairobi, P.O. Box 30197-00100, Nairobi, Kenya, Email: karsto2005@yahoo.com

\section{Abstract}

BACKGROUND: Majority of lower limb amputations performed in the African setting have been reported to be mainly due to trauma and neoplasms. These affect mainly young and therefore, fit individuals with lower risks of complications. Recent local studies show an increase in the incidence of cardiovascular diseases including peripheral vascular diseases. These are associated with higher rates of both systemic and amputation stump-related complications. There is however little published data in Africa on the outcomes of vascular lower limb amputations.

OBJECTIVE: To determine the early outcome of vascular lower limb amputations.

DESIGN: Descriptive prospective study, conducted between July 2003 and June 2004.

SETTING: The Kenyatta National Hospital, the largest referral and teaching hospital in Kenya.

SUBJECTS: All patients with gangrene of the lower limb due to occlusive peripheral vascular disease not caused by trauma or inappropriate limb splintage who were amputated at Kenyatta National Hospital during the study period were included.
OUTCOME MEASURES: These included the wound healing time, number of stump revisions, number of conversions to a higher amputation level, the thirty-day post-operative mortality and the hospitalization period.

CONCLUSION: While the findings of this study compare with other series, the prolonged hospital stay is of concern considering the younger average age of the patients.

\section{Introduction}

Lower limb amputations (LLA) due to vascular causes pose several management challenges as usually the patients are elderly and have co-morbidities that impact negatively on surgical outcomes. Most often, atherosclerosis is the aetiological factor leading to vascular occlusion, though the role of thrombophilias and Human immunodeficiency virus (HIV) has been appreciated (1-3). In Africa, trauma and tumours are widely considered to be the main aetiological factors leading to LLA. These are known to affect young and/or fit individuals making outcomes for survivors better. There is however increasing evidence that vascular diseases are on the rise and are contributing significantly to LLA $(4,5)$. Of concern are 
the costs involved in the investigation and management of vascular diseases and how this would affect amputation outcomes in the poor local economies. This study aimed at assessing the early outcome of vascular LLA at Kenyatta National Hospital.

\section{Patients and methods}

Design: Prospectively collected data on patients who underwent lower limb amputations due to occlusive peripheral arterial disease was analyzed.

Study site: Kenyatta National Hospital is the largest teaching and referral hospital in Kenya. It provides subsidized services to patients including diabetic care to orthopaedic and cardiovascular surgery.

Patients and methods: Study approval was sought from the local institution's ethical and research committee before data collection. Patients with critical limb ischaemia or gangrene and were scheduled for LLA were enrolled into the study.

Table 1: Age distribution and diabetic status of the patients

\begin{tabular}{|lcc|} 
& \multicolumn{2}{c|}{ No of. Patients } \\
Age class & Diabetic & Non-diabetic \\
\hline $15-30$ & 1 & 2 \\
$31-45$ & 0 & 10 \\
$46-60$ & 1 & 6 \\
Over 60 & 11 & 10 \\
\hline Total & 13 & 28 \\
\hline
\end{tabular}

Patients with traumatic vascular occlusion including inappropriate limb splintage in fracture management were excluded. Data captured included the age and gender of the patient, the dates of surgery and of discharge and pre-operative investigations. In all patients, a full blood count, urea and electrolytes and a random blood sugar were performed. Three had lipid profiles and none were investigated for thrombophilias or hyperhomocysteinemia. Only fourteen patients had limb arteriography or doppler ultrasonography done, meaning in the majority of cases the level of amputation was determined clinically. Other data included the level of amputation, number of stump revisions or conversions, under 30 days wound healing duration and the thirty-day and overall postoperative mortality. The data collected were coded and entered into the Statistical Package for Social Sciences (SPSS) for Windows ${ }^{\circledR}$ (version 11.5) Chicago, Illinois, for analysis. The results are presented as means and percentages.

\section{Results}

Forty one patients were included in the study. The ages ranged from 25 to 96 years (mean $58.4 \pm 17.6)$. Twenty five patients (61\%) were males. Thirteen patients (32\%) had diabetes mellitus (Table 1). Forty two amputations were performed, 8 of which were open. There were twenty below-knee(BK) and 19 above-knee(AK) amputations (1 bilateral), one hip disarticulation and the rest were foot amputations. Seven out of the 34 closed amputations required stump revisions without converting to a higher level.

Table 2: Stump revision and conversion according to amputation levels

\begin{tabular}{|lccc}
\hline Level & $\begin{array}{l}\text { No. of stumps } \\
\text { before conversion } \\
\text { (diabetic patients) }\end{array}$ & $\begin{array}{l}\text { No. of stumps after } \\
\text { conversion }\end{array}$ & $\begin{array}{l}\text { No. of closed amputation } \\
\text { stump wounds revised } \\
\text { but not converted }\end{array}$ \\
\hline Toe & 1 & 1 & 0 \\
Transmetatarsal & 1 & 0 & 1 \\
Tarsal & $3(2)$ & 1 & 0 \\
Below knee & 22 & 20 & 4 \\
Above knee & $14(8) 1$ bilateral & 19 & 2 \\
Hip disarticulation & 1 & 1 & 0 \\
\hline Total & 42 & 42 & 7
\end{tabular}


Table 3: Comparison of mean duration of hospital stay in various studies

$\begin{array}{lc}\text { Study (Region) } & \text { Mean duration of hospital stay (days) } \\ \text { Craig B.P.(16) (Australia) } & 24.7 \\ \text { Lim Tao S et al (17) (New Zealand) } & 10.1 \\ \text { Ashry H.R. et al (18) (United States of } & 15.9 \\ \text { America) } & 42 \\ \text { Van Houtum W.H. (191) (Netherlands) } & 26.5 \\ \text { Leung H.B. et al (6) (Hong Kong) } & 41.8 \\ \text { Present study (Kenya) } & \end{array}$

However, of the 22 initial BK amputations, five had to be converted to AK level (22.7\% conversion rate) while 3 of five foot amputations performed were converted to the BK level (Table 2). Ten patients $(24.4 \%)$ died during the entire study period due to complications related to sepsis. Of these, 3 had diabetes $(23 \%$ of all diabetics) while 7 were non-diabetic $(25 \%$ of non-diabetics). The thirty-day post-operative mortality was one percent. In twelve of the 31 surviving patients, the stumps had healed by 3 weeks post-operative $(38.7 \%)$ while in 20 patients $(64.5 \%)$, it took over 3 weeks for healing to take place with the longest taking 221 days. Most patients (64.5\%) were hospitalized for more than 4 weeks, with mean hospital stay of 41.8 days

\section{Discussion}

There is need to assess management outcomes of the vascular lower limb amputations (LLA) in our setting now that there are reports of an increase in cardiovascular diseases locoregionally and that a recentlocal study has shown that peripheral vascular diseases (PVD) are the leading indication for $\operatorname{LLA}(4,5)$. Vascular lower limb amputations affect mainly elderly patients, most often with multiple co-morbidities that require investigations not affordable to majority of our patients. These amputations have a lot of morbidity and mortality (6-8).

The present study assessed early outcome of vascular lower limb amputations in a setting where hitherto, LLA have been performed predominantly due to trauma and tumours (9). Most of the patients were young (mean age of 58.4 years), generally fit and lacked histories of comorbidities. Many patients in our setting cannot afford elaborate investigations for assessment of co-morbidities (5) as evidenced by the paucity of investigations done in the study. Despite this, most of the outcome measures except the duration of hospital stay compared to other series.

The distribution of amputation levels was similar to that in the published literature as the number of BKA and AKA performed was more or less the same giving a BKA: AKA ratio of 1:1 $(7,8)$. The stump revision rate was $21.2 \%$, most of which were due to wound sepsis mainly on BKA stumps. The conversion rate from BKA to AKA was 22\% also in keeping with other studies $(7,8)$. While the number of foot amputations was small, a significant proportion (3 out of 5), were converted to BKA, a finding similar to Leung et al (6) in Hong Kong. This could be attributable to the predominantly femoro-popliteal arterial occlusion in PVD.

The peri-operative mortality remains the same despite years of improvement in medical care, in excess of $10 \%$ in most studies (10-13). In this study, the overall mortality was $24.4 \%$. However, at $1 \%$ the thirty-day mortality was quite low, which is not surprising considering the relatively young age of the patients. Concerns however arise about the overall mortality in the period the study was carried out because even though most patients above 60 years were diabetic, majority of those accounting for this late mortality were non-diabetics. Local diabetes-related lower limb amputations have been associated with increased mortality due to problems of sugar control and sepsis (14).

The hospital stay has been identified as one of the key determinants of care costs associated with LLA (15). A mean duration of hospital stay of 41.8 days is quite long compared to most of the other studies (Table 3 ). These prolonged stays 
were as a result of delayed wound healing rates and more significantly, from delays in patient presentations and management as previously reported (20).

\section{Conclusion}

Patients undergoing lower limb amputations due to peripheral vascular disease are relatively young and therefore should be easier to rehabilitate. The long periods of hospitalization are of concern and highlight the need to focus on reducing delays in the management.

\section{Acknowledgement}

Kenyatta National Hospital management for allowing the conduction and publication of this study.

\section{References}

1. Vig S., Chitolie A., Bevan D., et al. The prevalence of thrombophilias in patients with symptomatic peripheral vascular disease. Brit J Surg. 2006; 93: 577-581.

2. Otieno C.F., Vaghela V, Ogola E.N., et al. Patterns of homocysteine in Kenyans with type II diabetes without overt cardiovascular disease at Kenyatta National Hospital, Nairobi. East Afr. Med. J. 2005; 82: 180-183.

3. Nair R., Robbs J.V., Chetty R., et al. Occlusive arterial disease in HIV-infected patients: A preliminary report. Eur J. Endovasc. Surg. 2000; 20: 353-357.

4. Kamotho C. and Ogola E.N. Cardiovascular risk factor profile of black Africans undergoing coronary angiography. East Afr. Med. J. 2004; 81: 82-86.

5. Awori K.O. and Ating'a J.E.O. Lower Limb Amputations at the Kenyatta National Hospital, Nairobi. East Afr. Med J. 2007; 84 : 121-126.

6. Leung H.B., Wong W.C., Wu F.C.J., et al. Perioperative and rehabilitation outcomes after lower limb amputation in elderly Chinese patients in Hong Kong. J. Orthoped. Surg. 2004; 12: 102-109.
7. Nehler M.R., Coll J.R., Hiatt W.R., et al. Functional outcome in a contemporary series of major lower extremity amputations. J. Vasc. Surg. 2003; 38: 7-14.

8. Abou-Zamzam Jr. A.M., Teruya T.H., Killen J.D., et al. Major lower extremity amputation in an academic vascular center. Ann Vasc. Surg. 2003; 17: 86-90.

9. Mbindyo B.S. Lower limb amputations in Kenyatta National Hospital. East Afr. Med. J. 1978; 55: 458-461.

10. Couch N.P., David J.K., Tilney N.L., et al. Natural history of the leg amputee. Amer. J. Surg. 1977. 133: 469-473.

11. Peng C.W. and Tan S.G. Perioperative and rehabilitative outcomes after amputation for ischemic leg gangrene. Amer. Acad. Med. Singapore. 2000; 29: 166-172.

12. Kazmers A., Perkins A.J., Jacobs L.A. et al. Major lower extremity amputation in Veteran Affairs Medical Centers. Ann. Vasc. Surg. 2000; 14: 216-222.

13. Gugulakis A.G., Lazaris A.M., Vasdekis S.N., et al. Rehabilitational outcome in patients with lower limb amputation because of arterial occlusive disease: Is it worth trying for lowest possible amputation level; A prospective study. Int. J. Rehab. Health. 2000; 5: 65-70.

14. Muyembe V.M. and Muhinga M.N. Major limb amputations in a Provincial General Hospital in Kenya. East Afr. Med. J. 1999; 76: 163-166.

15. Solomon C., Von Rij A., Barnett R., et al. Amputations in the surgical budget. N. Z. Med J. 1994; 107: 78-80.

16. Craig B.P. Diabetes-related lower limb amputations in Australia. Med. J. A. 2000; 173: 352-354.

17. Lim Tao S., Finlayson A., Thorpe J.M., et al. Outcomes of a contemporary amputation series. A N.Z. J. Surg. 2006; 300-305.

18. Ashry H.R., Lavery L.A., Amstrong D.G., et al. Cost of diabetes-related amputations in minorities. J. Foot Ankle Surg. 1998; 37: 186-190.

19. Von Houtum W.H., Lavery L.A. and Harkless L.B. The costs of diabetes-related lower extremity amputations in the Netherlands. Diabetic. Med. 1995; 12: 777-781.

20. Otieno C.F. and Atieno-Jalang'o G. Focus on delay as a strategy for case designs and evaluation of diabetic foot ulcers in developing countries. East Afr. Med. J. 2005; 82: 204-207. 